\title{
Intravenous Piggyback Solution Dosage Form
}

National Cancer Institute

\section{Source}

National Cancer Institute. Intravenous Piggyback Solution Dosage Form. NCI Thesaurus.

Code C68967.

A solution intended for intravenous administration simultaneously with an established compatible maintenance infusion drug by a mutual intravenous access. 